\title{
Retrospective Study of Management of Near Total Avulsion of Auricles and Review of the Literature
}

\author{
KARAM A. ALLAM, M.D.*; MOHAMMED E.A. MOHAMMED, M.D.**; MOSTAFA M. HAREDY, M.D.* and \\ AHMED G. ABDELMEGEED, M.D.*
}

The Departments of Plastic Surgery* and Otolaryngology - Head \& Neck Surgery**, Faculty of Medicine, Sohag University, Egypt

\begin{abstract}
Objective: Management of the near-total auricular avulsion injury is a difficult challenge. There are several techniques for the proper treatment of such injuries with variable results. We present a series of seven cases of traumatic auricular near total avulsion with a narrow flap base. This is accompanied with a review of literature of similar conditions.

Patients and Methods: This work presents a retrospective study of patients with traumatic auricular amputation, who were admitted to the emergency department at Sohag University Hospital, in the period from March 2015 to November 2019 , with traumatic auricular avulsion. Patients' files were reviewed for demographic data, trauma details, operative notes, and post-operative results. Only patients with neartotal auricular avulsion.

Results: Seven patients (6 males and one female) were included with complete records and fulfilled criteria. The mean age at the time of trauma was 25.8 years. Early postoperative venous congestion of the reattached ear was reported in two patients. All cases were successfully reattached without tissue loss of the repositioned tissue or significant shrinkage postoperatively. The literature presented twelve articles reporting 17 patients, where venous congestion was the most common complication after the repair $(35.3 \%)$.

Conclusions: The entire ear can survive based on a small, inferiorly based pedicle with favorable results and without severe complications.
\end{abstract}

Key Words: Ear - Auricle - Reattachment - Amputation Pedicle.

Disclosure: No conflict of interest.

\section{INTRODUCTION}

Although traumatic ear amputations and avulsions are commonly seen in emergency departments, [1] near-total avulsion is a relatively uncommon but severe injury [2]. It can result in functional and aesthetic disabilities, causing a patient's significant psychological distress [3]. The delicate skin and vasculature with complex cartilaginous contours complicate the management and restoration of acceptable aesthetic results [4]. Several techniques for repairing the avulsed auricle have been prescribed with variable success rates [5]. Standardizing an optimum reconstructive procedure has been challenging due to the low frequency, complexity, and high variability in the management [6].

The suitable surgical technique for each case is the key for post-operative survival of severed auricle [1]. Therefore; numerous techniques have been described trying to optimize the survival chance of the replanted and reattached auricle. The vascular anatomy of the ear and mechanism of the injury is crucial in the decision for the proper reconstruction technique [7].

The microvascular repair has higher success compared to the other methods [2]. Butit is more complicated and postoperative venous congestion may occur. This is due to the small vessel size and difficult to find vessels stumps after trauma. Also, it is a lengthy procedure that requires a well-trained micro-surgeon who may not be available in all centers $[\mathbf{5 , 6}$. However, there is no single easy procedure to solve the problem in all cases.

Herein, we present our experience in a case series of seven patients with near-total auricular avulsion with narrow, inferiorly based pedicles. Reattachment technique was performed. The technique is fully described with the post-operative management and outcome. A comprehensive review of literature of reattachment of avulsed ear was conducted.

\section{PATIENTS AND METHODS}

This is a retrospective study of patients who were presented to the Emergency Unit at Sohag University Hospital (SUH), in the period from March 2015 to November 2019, with traumatic 
auricular avulsion. Patients' files were reviewed for demographic data, trauma details (type of trauma, the time between auricular injury and reattachment surgery, the status of the traumatized auricle, and other craniofacial or extra-craniofacial trauma). Status of traumatized auricle, vascularity and tissue loss was examined preoperatively. All cases were operated within 6 hours after trauma. Only patients with near-total auricular avulsion were included. We excluded significantly crushed auricles.

\section{Operative procedure:}

The operation was performed under general or local anesthesia as early as possible. Intravenous antibiotics started preoperatively. In the case of local infiltration anesthesia, $0.5 \%$ lidocaine without adrenaline was used. The wounds were adequately irrigated and minimally debrided. The ear cartilage was sutured by 5/0 PDS sutures, and the skin was sutured intermittently by 6-0 Prolene. A stent was applied in the external auditory canal to maintain its patency with a very light dressing.

\section{Post-operative management and follow-up:}

Post-operative antibiotics and analgesic/antiinflammatory were used for one week. Anticoagulants (Clexane $0.4 \mathrm{ml}$, every 12 hours) were used for 2 days and ear circulation was monitored every 4 hours during the first 2 days then low-dose aspirin
$100 \mathrm{mg}$ daily after discharge for one week. Patients were discharged on the third or fourth day postoperatively, and the sutures were removed after 1 week. Next follow-up visits at 2 weeks, 4 weeks and 12 weeks postoperatively, minimum followup is 3 months.

\section{Literature review:}

A literature search was performed on Pub Med using search terms "Ear -Auricle - Subtotal - Neartotal - Partial - Incomplete - Pedicle - Amputation - Laceration - Avulsion -replantation - Reattach Non-microsurgical". English literatures with full data were included. The age, sex, side, type of trauma, and size of pedicle and complication were collected.

\section{RESULTS}

Seven patients with complete records fulfilled the criteria and were included in this study. Patients' characteristics are analyzed and reported in Table (1). There was male predominance $(85.7 \%)$, and the mean age was 25.8 years. Motor car accident (MCA) was the main cause in $57.1 \%$. All cases were inferiorly based pedicle. Pedicle width ranged from 8 to $19 \mathrm{~mm}$. All cases were operated early after injuries. The traumatized auricles were in good conditions, as regard skin color and bleeding edges at the distal end. We did not examine for artery or veins in the pedicle.

Table (1): Our cases demographic and clinical data.

\begin{tabular}{|c|c|c|c|c|c|c|c|}
\hline Cases & Age & Sex & Side & $\begin{array}{l}\text { Type of } \\
\text { trauma }\end{array}$ & $\begin{array}{l}\text { Inferior based } \\
\text { pedicle width }\end{array}$ & $\begin{array}{l}\text { Associated craniofacial or } \\
\text { other extra-cranial trauma }\end{array}$ & $\begin{array}{l}\text { Postoperative } \\
\text { complication }\end{array}$ \\
\hline Case 1 & 19 & $\mathrm{M}$ & Left & $\mathrm{MCA}$ & $8 \mathrm{~mm}$ & None & $\begin{array}{l}\text { Venous congestion improved with } \\
\text { multiple stabbing }\end{array}$ \\
\hline Case 2 & 25 & M & Left & Assault & $9 \mathrm{~mm}$ & Non & None \\
\hline Case 3 & 45 & $\mathrm{M}$ & Left & $\mathrm{MCA}$ & $12 \mathrm{~mm}$ & Non & $\begin{array}{l}\text { Venous congestion improved with } \\
\text { treatment }\end{array}$ \\
\hline Case 4 & 33 & M & Left & Assault & $14 \mathrm{~mm}$ & None & None \\
\hline Case 5 & 27 & $\mathrm{~F}$ & Left & Assault & $10 \mathrm{~mm}$ & None & None \\
\hline Case 6 & 20 & M & Right & MCA & $16 \mathrm{~mm}$ & None & None \\
\hline Case 7 & 12 & M & Right & MCA & $19 \mathrm{~mm}$ & None & None \\
\hline
\end{tabular}

Early postoperatively, venous congestion of the repaired ear was reported in two patients $(28.6 \%)$, one of them required multiple needle punctures, and both of them improved with no residual vascular compromise. The second case with venous congestion improved on pentoxiphylline orally (400mg q8h) and vitamin E (400 IU daily orally) for 2 weeks. At follow-up, the entire ear remained entirely viable with no tissue loss. Follow-up with the patient at 2 weeks after the operation showed ear survival in $100 \%$ of the patients.

A successful reattachment was achieved in all cases. The auricles healed completely without tissue loss or necrosis. No complications have been noted after 3 months of follow-up with good morphological results as regard auricle shape, projection, size, and elasticity, and without external auditory canal stenosis. All patients had normal ears and were highly satisfied (Figs. 1,2). 


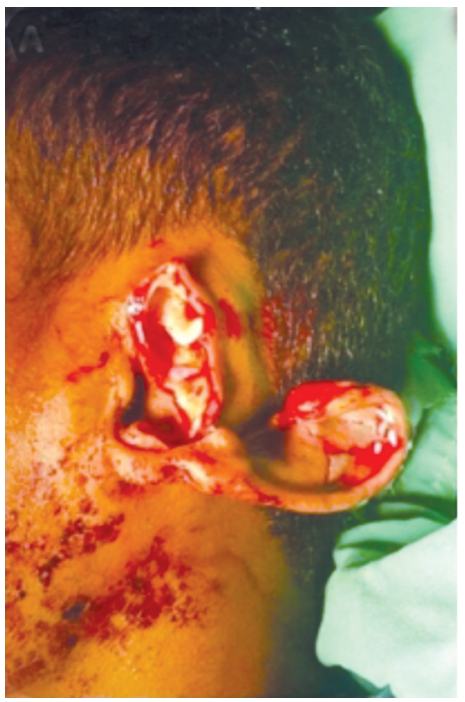

(A)

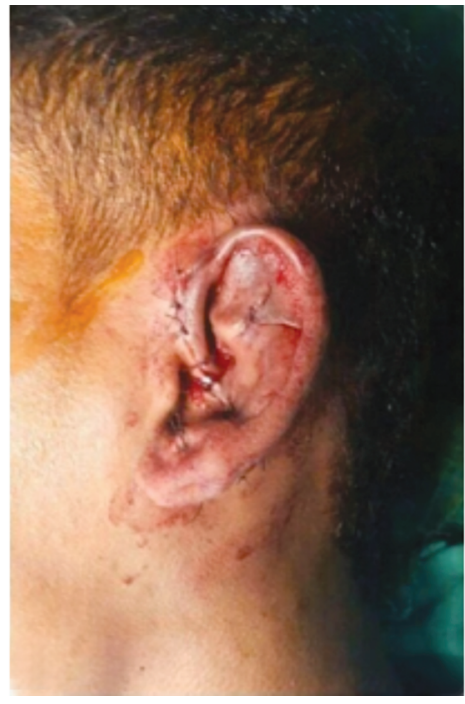

(B)

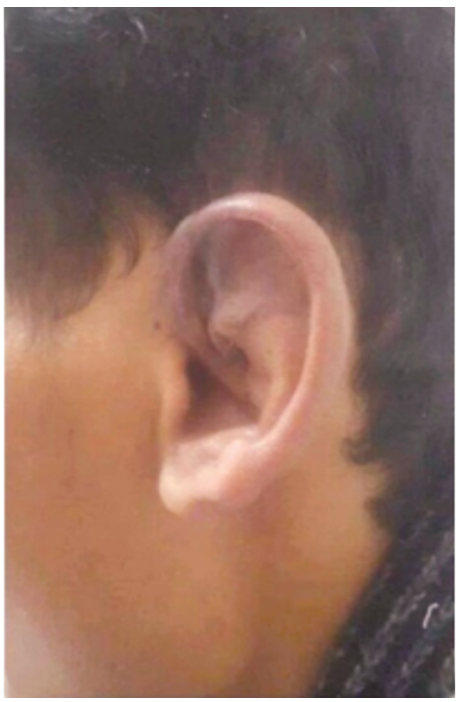

(C)

Fig. (1): (A) Preoperative view immediate after MCA trauma with $12 \mathrm{~mm}$ inferior based pedicle. (B) After reattachment. (C) Post-operative after 3 months with normal appearance.

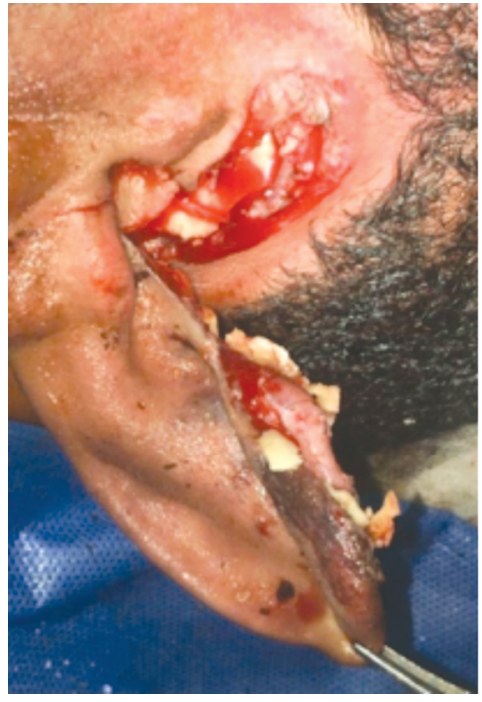

(A)

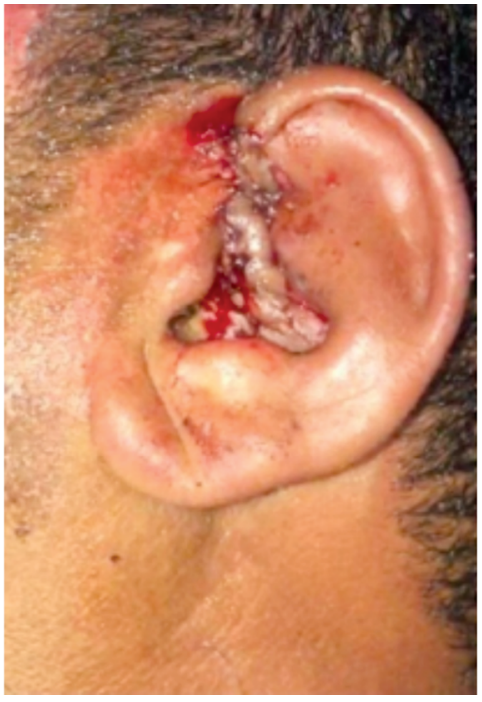

(B)

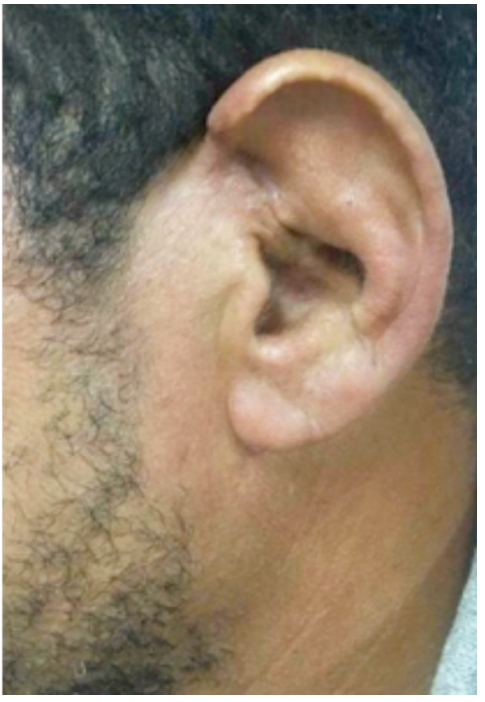

(C)

Fig. (2): (A) Pre-operative view immediate after assault from others with $14 \mathrm{~mm}$ inferior based pedicle. (B) After reattachment. (C) Post-operative after 3 months with normal appearance.

\section{Review of literature:}

In total, 12 papers 1, 7-17 were included while 2418-42 papers were excluded due to incomplete data, non-English or complete amputation. The total number of patients identified in this review was 17 , with male predominance $(n=14 ; 82.3 \%)$. The left side was the more commonly affected side $(\mathrm{n}=10 ; 58.8 \%)$. The commonest cause of injury was motor car accident $(\mathrm{n}=8 ; 47 \%)$, followed by assault ( $n=3 ; 17.6 \%)$, industrial $(n=3 ; 17.6 \%)$, animal bites $(n=2 ; 11.8 \%)$, and fall $(n=1 ; 6 \%)$. Neartotal avulsion was either superiorly based pedicle $(\mathrm{n}=8 ; 47 \%)$, inferiorly based pedicle $(\mathrm{n}=8 ; 47 \%)$ or superiorly and inferiorly base in $(n=1 ; 6 \%)$. Good results without complications were reported in 8 patients (47\%). Venous congestion was reported in 6 patients $(35.3 \%)$ and was adequately treated either with medical or HBOT or leech. Lobule demarcation in superiorly based avulsion was reported in 3 patients $(17.6 \%)$ and two of them treated with local flaps. Pedicle width ranged from 3 to $15 \mathrm{~mm}$ in superiorly based and 5 to $30 \mathrm{~mm}$ in inferiorly based. The collected data is expressed in the Table (2). 
Table (2): Literature cases demographic and clinical data.

\begin{tabular}{|c|c|c|c|c|c|c|}
\hline References & Age & Sex & Side & $\mathrm{AE}$ & Pedicle width & $\begin{array}{l}\text { Post-operative } \\
\text { complications }\end{array}$ \\
\hline Albdour et al., 2021 [8] & 55 & $\mathrm{M}$ & Right & MCA & $5 \mathrm{~mm}$ superior based & $\begin{array}{l}\text { Venous congestion improved } \\
\text { after } 12 \text { days }\end{array}$ \\
\hline \multirow[t]{5}{*}{ D'Arcangelo et al., 2020 [9] } & 34 & M & Left & MCA & $7 \mathrm{~mm}$ superior based & Necrotic area of the lobule \\
\hline & 31 & M & Right & MCA & $25 \mathrm{~mm}$ inferior based & NO \\
\hline & 50 & M & Right & Assault & $\begin{array}{l}20.5 \mathrm{~mm} \text { superior and } \\
\text { inferior based }\end{array}$ & NO \\
\hline & 34 & $\mathrm{M}$ & Left & Assault & $10 \mathrm{~mm}$ inferior based & NO \\
\hline & 32 & M & Left & MCA & $6 \mathrm{~mm}$ inferior based & NO \\
\hline Zhang et al. 2018 [6] & 16 & M & Left & Assault & $5 \mathrm{~mm}$ inferior based & NO \\
\hline Kemaloglu et al. 2015 [7] & 57 & M & Left & Industrial & $5 \mathrm{~mm}$ inferior based & $\begin{array}{l}\text { Venous congestion improved } \\
\text { after } 3 \text { days }\end{array}$ \\
\hline Aremu, 2014 [8] & 12 & M & Right & MCA & $20 \mathrm{~mm}$ inferior based & No \\
\hline Bada and Pope,2013 [9] & 4 & M & Right & Animal bite & $30 \mathrm{~mm}$ inferior based & $\begin{array}{l}\text { Venous congestion and HBOT } \\
\text { was used }\end{array}$ \\
\hline Ozcelik et al., 2009 [10] & 36 & M & Right & MCA & $6 \mathrm{~mm}$ superior based & No \\
\hline \multirow[t]{2}{*}{ Erdmann et al., 2008 [11] } & 23 & $\mathrm{~F}$ & Left & MCA & $15 \mathrm{~mm}$ superior based & $\begin{array}{l}\text { Lobule demarcation+ anterior } \\
\text { based postauricular flap }\end{array}$ \\
\hline & 3 & M & Left & Fall & $10 \mathrm{~mm}$ superior based & Congestion and leech therapy \\
\hline $\begin{array}{l}\text { Komorowska-Timek and } \\
\text { Hardesty, } 2005 \text { [12] }\end{array}$ & 35 & M & Left & Industrial & $7 \mathrm{~mm}$ inferior based & Congestion and leech therapy \\
\hline Yotsuyanagi et al., 2001 [13] & 42 & $\mathrm{~F}$ & Left & Industrial & $10 \mathrm{~mm}$ superior based & No \\
\hline Safak and Kayikcioglu, 1998 [14] & 40 & M & Right & MCA & $3 \mathrm{~mm}$ superior based & Lobule demarcation+ local flap \\
\hline Bernstein and Nelson, 1982 [15] & 28 & $\mathrm{~F}$ & Left & Animal bite & $10 \mathrm{~mm}$ superiorly based & Venous congestion \\
\hline
\end{tabular}

\section{DISCUSSION}

The auricle is highly susceptible to trauma due to its lateral protrusion from the head. The unique and complex auricular anatomy requires high reconstructive standards to achieve an aesthetic good result [6].

Management of the near-total auricular avulsion injury is a difficult challenge. There are no universally agreed guidelines for the proper treatment of such injuries [11]. The main objective is to obtain the best possible cosmetic result. Sometimes unsatisfactory outcomes occur due to the unique three-dimensional auricular structure and its anatomical characteristics [1].

Several reconstructive surgical procedures have been published, including microvascular replantation, simple non-microvascular reattachment as a composite graft, local skin flaps, methods using pocket techniques, and staged autologous reconstruction with rib cartilage $[2,5,6]$. The success in such cases largely depends on the initial choice of the appropriate surgical approach since many factors influence the surgical outcome [11].

Ear trauma affects mainly younger and active groups of the population [5]. In this study, the age of the involved patients ranged from 12 to 45 years (mean 25 years). Age of the patient may contribute to treatment selection criteria and prognosis. Younger age has better healing and requiring good aesthetic outcomes. Regarding gender affection, men were predominantly affected, which can be explained by their lifestyle and more outdoor exposure in our community. Traffic accidents are the most frequent causes for this challenging ear trauma. Assault is also a common cause for ear amputation, the causative agents being mostly knives and human bites.

Satisfactory post-operative results were achieved in the primary reattachment technique. The classic composite graft is indicated only in the presence of a wholesome skin bridge [5]. Neartotal avulsion with a pedicle has been reported in literature either with inferior or superior pedicles [7]. The reattachment survival in near-total ear avulsion depends on pedicle width and feeding vessels. Better outcomes can be expected in cases with a sharp cut, minimal tissue loss, minimal crush injuries, and early presentation after trauma. No need for pedicle examination for the artery or vein provided that an intact skin pedicle, good skin color, and active bleeding edges can be appreciated. These can be good prognostic findings suggesting good blood circulation [9]. In the literature, reattachment was done for several cases with superior pedicle ranged from $3 \mathrm{~mm}$ to $15 \mathrm{~mm}$ and inferior pedicle ranged from $5 \mathrm{~mm}$ to $30 \mathrm{~mm}$ [1,7-15]. The 
narrowest superior and inferior based pedicle reported with successful outcomes was $3 \mathrm{~mm}$ and $5 \mathrm{~mm}$, respectively $[\mathbf{6 , 7 , 1 6}]$. Hence reattachment techniques is simple with good comparable outcomes and even with narrow residual pedicles.

The extensive vascular networks, low cartilage metabolic demands, and thin skin allow auricular survival with any residual single arterial and venous supply [26]. Therefore, simple reattachment and venous congestion care until neovascularization can achieve successful reconstruction without microsurgery [13].

Complications range from merely post-operative edema, venous congestion, epidermolysis, up to partial necrosis [7]. Fora successful reattachment, a multimodal therapy approach consisting of aggressive medical therapy with broad-spectrum intravenous antibiotics and anticoagulation, in conjunction with an efficient surgical approach and proper post-operative care, is needed.

\section{Conclusion:}

Near-total ear avulsion is a rare but serious and challenging trauma. Simple reattachment is a safe and simple technique, as long as, the case is properly selected. Good aesthetic outcome has been observed after 3 months follow-up.

\section{Declaration of patient consent:}

Patients' consent forms were obtained to report his/her/their images and other clinical information in the journal. They understand that their names will not be published, and due efforts will be made to conceal their identity.

\section{REFERENCES}

1- Zhang C., Teng L., Xu J.J., et al.: Incomplete Ear Amputation. Journal of Craniofacial Surgery, Nov. 1; 29 (8): 2231-3, 2018.

2- Gailey A.D., Farquhar D., Clark J.M., et al.: Auricular avulsion injuries and reattachment techniques: A systematic review. Laryngoscope Investigative Otolaryngology, June 5; (3): 381-389, 2020.

3- Abd-Almoktader M.A.: Nonmicrosurgical single-stage auricular replantation of amputated ear. Ann. Plast. Surg., 67: 40-43, 2011.

4- Bozan N., Sakin Y.F., Bozkus F., et al.: Reattachment of a partially amputated ear without microsurgery. JPMA. The Journal of the Pakistan Medical Association, Sep. 1; 66 (9): 1185-7, 2016.

5- Steffen A., Katzbach R. and Klaiber S.: A comparison of ear reattachment methods: A review of 25 years since pennington. Plast. Reconstr. Surg., 118: 1358-1364, 2006.

6- Bai H. and Tollefson T.T.: Treatment strategies for auricular avulsions: Best practice. JAMA Facial Plastic Surgery, Jan 1; 16 (1): 7-8, 2014.
7- Kemaloğlu C.A., Kılıç F. and Günay G.K.: Reconstruction of a subtotally amputated auricle with a very narrow inferior pedicle. Case Reports in Plastic Surgery and Hand Surgery, Dec. 23; 2 (3-4): 77-9, 2015.

8- Albdour M., Ammar H.M., Alnaser M.M., Alzaben F.S. and Malek S.: Non-microvascular Successful Management of Near-total Ear Avulsion. Plastic and Reconstructive Surgery Global Open, 9.1, 2021.

9- D'Arcangelo M., Al-Ali M.A. and Abu-Zidan F.M.: Primary Reattachment of Near-Complete Ear Amputation: A Successful Outcome. Ear, Nose \& Throat Journal, 0145561320982170, 2020.

10- Aremu S.K.: Nonmicroscopic reconstruction of subtotally amputated/torn auricles: Report of 3 cases. ENT-Ear, Nose \& Throat Journal, Feb. 1; 93 (2): 1-3, 2014.

11- Bada A.M. and Pope G.H.: Use of hyperbaric oxygen as adjunct in salvage of near-complete ear amputation. Plastic and Reconstructive Surgery Global Open, Apr. 1 (1), 2013.

12- Ozcelik D., Unveren T. and Toplu G.: Subtotal ear amputation with a very narrow pedicle: A case report and review of the literature. Ulus Travma Acil Cerrahi Derg., 15: 306-310, 2009.

13- Erdmann D., Bruno A.D., Follmar K.E., et al.: The helical arcade: Anatomic basis for survival in near-total ear avulsion. J. Craniofac. Surg., 20: 245-248, 2008.

14- Komorowska-Timek E. and Hardesty R.A.: Successful reattachment of a nearly amputated ear without microsurgery. Plast. Reconstr. Surg., 121: 165e-169e, 2005.

15- Yotsuyanagi T., Yamashita K., Watanabe Y., et al.: Reconstruction of a subtotally amputated auricle: A case report. Scand J. Plast. Reconstr. Surg. Hand Surg., 35: 425-428, 2001.

16- Safak T. and Kayikcioglu A.: A traumatic ear amputation attached with a narrow pedicle. Ann. Plast. Surg., 40: 106-7, 1998.

17- Bernstein L. and Nelson R.H.: Replanting the severed auricle. Arch. Otolaryngol., 108: 587-590, 1982.

18- Tyagi B.S. and Tyagi S.: Reimplantation of an amputated pinna: A case report and review of literature. Indian Journal of Otology, Jul. 1; 23 (3): 208, 2017.

19- Tomita K., Hosokawa K., Yano K., Takada A., Kubo T. and Kikuchi M.: Dermal vascularity of the auricle: Implications for novel composite grafts. J. Plast. Reconstr. Aesthet. Surg., 62: 1609-15, 2009.

20- Ihrai T., Balaguer T., Monteil M.C., et al.: Surgical management of traumatic ear amputations: Literature review. In Annales de chirurgie plastique et esthetique, Apr. (Vol. 54, No. 2, p. 146), 2009.

21 - Nicolay N.H., Bruno A.D., Follmar K.E., et al.: Subtotale Amputation des Ohrs. Der Chirurg, Sep. 1; 78 (9): 835 9, 2007.

22- Kyrmizakis D.E., Karatzanis A.D., Bourolias C.A., et al.: Nonmicrosurgical reconstruction of the auricle after traumatic amputation due to human bite. Head Face Med., 2: 45, 2006.

23- Haug M., Schoeller T., Wechselberger G., et al.: External ear injuries-classification and therapeutic concept. Unfallchirurg, 104: 1068-1075, 2001. 
24- Godwin Y., Allison K. and Waters R.: Reconstruction of a large defect of the ear using a composite graft following a human bite injury. Br. J. Plast. Surg., 52: 152-154, 1999.

25- Komuro Y. and Kawanabe T.: The microsurgical reconstruction of an incompletely amputated ear: A case report. Jpn. J. Plast. Reconstr. Surg., 38: 935-9, 1995.

26- Nath R.K., Kraemer B.A. and Azizzadeh A.: Complete ear replantation without venous anastomosis. Microsurgery, 18 (4): 282-5, 1998.

27- Kind G.M., Buncke G.M., Placik O.J., et al.: Total ear replantation. Plast. Reconstr. Surg., 99 (7): 1858-67, 1997.

28- Pribaz J.J., Crespo L.D., Orgill D.P., et al.: Ear replantation without microsurgery. Plast. Reconstr. Surg., 99 (7): 1868$72,1997$.

29- Fuleihan N.S., Natout M.A., Webster R.C., et al.: Successful replantation of amputated nose and auricle. Otolaryngology-Head and Neck Surgery, Jul. 97 (1): 1823, 1987.

30- Juri J., Irigaray A., Juri C., et al.: Ear replantation. Plast. Reconstr. Surg., 80: 431-5, 1987.

31- Bardsley A.F. and Mercer D.M.: The injured ear: A review of 50 cases. British Journal of Plastic Surgery, Oct. 1; 36 (4): 466-9, 1983.

32- Burgess L.P., Novia M.V., Frankel S.F., et al.: Avulsions of the auricle. Ear Nose Throat J., 64: 546-548, 1985
33- Tomono T. and Hirose T.: Treatment of the subtotally amputated auricle. Jpn. J. Plast. Reconstr. Surg., 23: 416,1980 .

34- Lewis E.C. 2nd and Fowler J.R.: Two replantations of severed ear parts. Plast. Reconstr. Surg., 64 (5): 703-5, 1979.

35- Larsen J., Pless J. and Larsen J.: Replantation of severed ear parts. Plastic and Reconstructive Surgery, Feb. 1; 57 (2): 176-9, 1976

36- Baudet J.: Successful replantation of a large severed ear fragment. Plast. Reconstr. Surg., 51 (1): 82, 1973.

37- Gilford G.H.: Replantation of severed part of an ear. Plastic and Reconstructive Surgery, Feb. 1; 49 (2): 2023, 1972 .

38- McDowell F.: Successful replantation of a severed half ear. Plast. Reconstr. Surg., 48 (3): 281-3, 1971.

39- Musgrave R. and Garrett W.: Management of avulsion injuries of the external ear. Plast. Reconstr. Surg., 40: 534-539, 1967.

40- Clodius L.: Local hypothermia for the avulsed external ear. Br. J. Plast. Surg., 21: 250-2, 1968.

41- Brown W.J.: Extraordinary case of horse-bite; the external ear completely bitten off and successfully replaced. Lancet, 67: 1533-1534, 1898.

42- Steffen A., Klaiber S., Katzbach R., et al.: Zur Epidemiologie von Ohrmuschelverletzungen [Epidemiology of auricular trauma]. Handchir Mikrochir Plast Chir., 39 (2): 98-102. doi: 10.1055/s-2007-965136, 2007. 